\title{
Influence of stabilisers on the unconfined compressive strength of a fine soil
}

Mingwei Feng BEng

PhD student, Ningbo Nottingham New Materials Institute, University of Nottingham Ningbo China, Ningbo, China

Shu Liu BEng, MSc, PhD

Research Fellow, Ningbo Nottingham New Materials Institute, University of Nottingham Ningbo China, Ningbo, China; Postdoctoral Research Fellow, State Key Laboratory for GeoMechanics and Deep Underground

Engineering, China University of Mining and Technology, Xuzhou, China
Juan Wang BEng, MSc, PhD

Associate Professor, Ningbo Nottingham New Materials Institute, University of Nottingham Ningbo China, Ningbo, China (corresponding author: juan.wang@nottingham.edu.cn)

Yunfeng Hu BEng, MSc

Engineer, Ningbo Transportation Engineering Construction Group Co. Ltd, Ningbo, China

In foundation engineering, weak subgrade soils are usually improved by adding several stabilisers to satisfy construction requirements, but the influence degree of each stabiliser on the strength of the stabilised soils is rarely studied. In this study, a series of unconfined compressive strength tests was conducted on a fine soil stabilised with various proportions of cement, lime, fly ash and gypsum. The influences of the four stabilisers were investigated through quantitative analysis and grey correlation analysis. The quantitative analysis examined the trends of the unconfined compressive strength with increasing contents of different stabilisers. It was found that there existed optimum fly ash and gypsum contents in this study. Also, the cement had the highest positive impact on the unconfined compressive strength. In the grey relational analysis, different normalisation methods were utilised, and it was found that the normalisation method and the trend of the strength with rising stabiliser content affected the order of the impact of various stabilisers. The grey relational analysis with a range-normalisation method provided a reasonable order of impact in this study.

\author{
Notation \\ $i \quad$ reference number of each stabiliser \\ $j \quad$ element number in a sequence \\ $m$ group test number \\ $n \quad$ total number of stabilisers \\ $r_{i} \quad$ relevancy \\ $x_{0}(j)$ reference sequence after normalisation \\ $x_{i}(j) \quad$ sequence after normalisation \\ $y_{0}(j)$ reference sequence \\ $y_{0}^{m} \quad$ element in a reference sequence \\ $\bar{y}_{i} \quad$ average value of comparison sequence \\ $y_{i}(1) \quad$ initial value of a comparison sequence \\ $y_{i}(j) \quad$ comparison sequence \\ $y_{i}^{m} \quad$ element in a comparison sequence \\ $\Delta_{i}(j) \quad$ absolute difference between the normalised reference \\ and normalised comparison sequences \\ $\Delta_{\max } \quad$ maximum value of $\Delta_{i}(j)$ \\ $\Delta_{\text {min }} \quad$ minimum value of $\Delta_{i}(j)$ \\ $\xi_{i}(k) \quad$ relational coefficient
}

\section{Introduction}

Weak subgrade soils are often mixed with stabilisers to satisfy construction requirements. The most commonly used stabilisers are cement and lime. As noted by many researchers (e.g. Bell, 1995; Prusinski and Bhattacharja, 1999), cement-treated soils gain their early strength mainly due to hydrolysis and hydration reactions, while their long-term strength is attributed to pozzolanic reactions. As for lime, ion-exchange reactions can take place immediately (Bell, 1996; Sherwood, 1993). Meanwhile, pozzolanic reactions between the remanent calcium hydroxide and active clay minerals can also improve strength, but their reaction rate is relatively slow (Petry and Little, 2002). In light of geotechnical sustainability, alternative materials such as fly ash and gypsum are also applied in many studies (Purwanto et al., 2020). It was found that an alkaline environment can remarkably improve the degree of activity of fly ash and accelerate the hydration process, and therefore, more cementitious gels and thus a higher strength (Taştan, 2005) can be obtained. Considering that the hydroxide ion content in fly ash is limited, lime or other alkaline excitation agents are always used as supplements (e.g. Chen et al., 2013; Kumar, et al. 2007; Sivapullaiah and Jha, 2014). Other combinations of stabilisers are also used by many researchers. For example, cement or fly ash is always applied along with lime to facilitate its pozzolanic reaction (e.g. Åhnberg and Holm, 2009; Indraratna et al., 1995; Jauberthie et al., 2010; Ouhadi et al., 2014). For the combination of cement and fly ash, cement works as a stabiliser as well as an alkali activator for fly ash (Kogbara et al., 2013; Wang and $\mathrm{Xu}, 2013$ ). Also, adding a proper portion of gypsum as the supplement can help fill the voids in the stabilised soil and thus, improve its strength (Huang and Hu, 1998; Jin et al., 2014). In addition, peat ash, silica sand, sludge ash and other emerging materials can also be used as a stabiliser or supplement for soil stabilisation (e.g. Lin et al., 2007; Mousavi and Wong, 2015).

Nowadays, there are various stabilisers available in the market, and many studies have been conducted to examine the relationship between the stabiliser content and the strength of the stabilised soil considering one or more stabilisers or to select optimum combinations for construction projects. For instance, unconfined compressive strength (UCS), one of the key indicators of the strength of stabilised soils, was studied by Tsuchida and 
Tang (2015) for a cement-treated marine clay to obtain the required cement content. Kolay and Pui (2010) investigated the impacts of gypsum and fly ash contents on the UCSs of stabilised muddy soils, and the best combination was recommended based on quantitative analyses. Nevertheless, few scholars have studied the impact degree of each component in a combination of various stabilisers on the strength of stabilised soils. The impact order can help engineers quickly select stabilisers for similar cases.

Grey relational analysis has been widely used to analyse the relationship between several sequences, and the grade of correlation can be determined, known as the grey relational coefficient (Deng, 1989; Gau et al., 2006). In the field of civil engineering, this method has been applied by researchers to study the impact degrees of different factors on a target objective, thus, providing guidance for engineering applications. For instance, Wang et al. (2004) studied the correlations between the stability of slide slopes and some sensitive factors. They found that the effects of cohesion and friction angle of the materials are more significant than those of earthquake acceleration and water level in reservoirs. For a cut-and-fill pavement foundation, Su et al. (2012) ranked the relations between the slope stability and possible influencing factors, including the properties of fills and the geometry of the embankment slope. He et al. (2014) investigated the effect of particle characteristics on the compressive strength for lightweight aggregate concretes and provided suggestions on the optimisation strategy based on grey relational analyses. Zhang and Zhang (2007) considered the effect of different particle fractions of slag powders on the strength of slag cements, and suggestions were proposed to help slag cement gain more strength. It is worth mentioning that one important process in grey relational analysis is the normalisation of source data, since the comparative sequences usually have different dimensions and their numerical values may vary greatly. Several different normalisation methods have been used in previous research studies, such as the range method (e.g. Su et al., 2012), average range method (e.g. He et al., 2014; Zhang and Zhang, 2007), maximisation or minimisation methods (e.g. Mishra et al., 2015) and initialisation method (e.g. Feng et al., 2014). Despite those applications, none of the research studies have examined the effects of different normalisation methods on grey relational analysis results. Also, the applicability of grey relational analysis in identifying the impact degree of various stabilisers on soil strength is yet to be investigated.

In this study, cement, fly ash, lime and gypsum were used as the stabilisers for a fine soil. Their effects on the UCS of the stabilised soil were researched through both quantitative analysis and grey relational analysis. The influence of various normalisation methods was also studied.

\section{Experimental procedure}

\section{Materials}

The fine soil used in this study was taken from an expressway construction site in Ningbo, China, the location of which is shown in Figure 1. Figure 2 shows the gradation curve of the soil

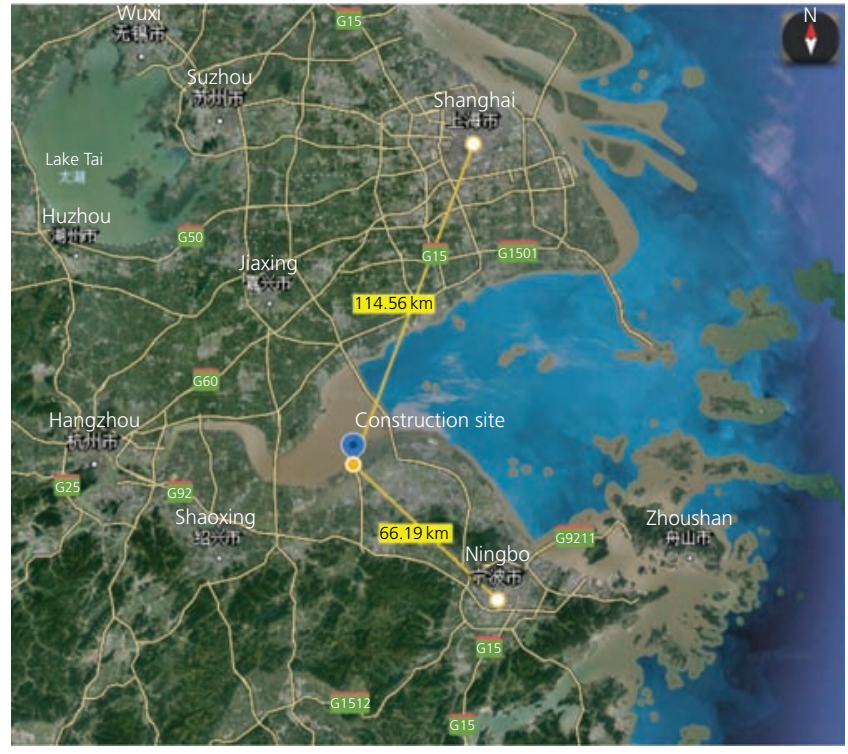

Figure 1. Location of the construction site

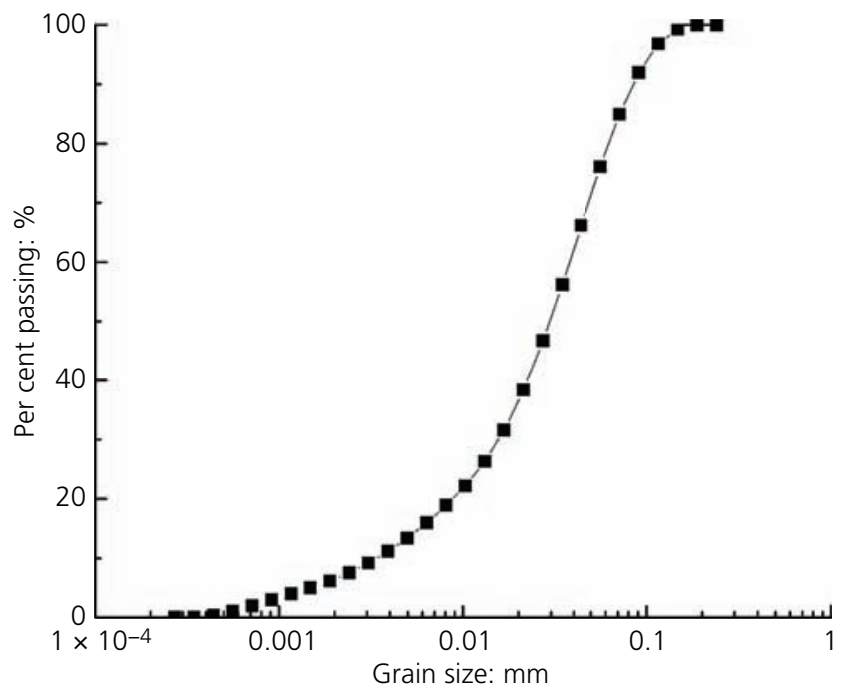

Figure 2. Soil gradation

obtained by using a Bettersize 2000 laser particle size analyser. The liquid limit, plastic limit and plastic index of the soil are $24.0 \%, 14.3 \%$ and 9.7 , respectively. It can be classified as CL according to the British standard BS 5930:2015 (BSI, 2015). Light compaction tests were carried out on the fine soil according to the standard Proctor compaction test procedure in the British standard BS 1377-2:1990 (BSI, 1990a). It was found that the maximum dry density and the optimum moisture content of the fine soil were $1.81 \times 10^{3} \mathrm{~kg} / \mathrm{m}^{3}$ and $9.4 \%$, respectively.

Four stabilisers, cement, fly ash, quick lime and gypsum, were used in this project. The Portland cement CEM I $42.5 \mathrm{~N}$ was 
Table 1. Chemical composition of the class II fly ash

$\begin{array}{lcccccc}\text { Component } & \text { Loss on } & \text { Silicon dioxide } & \text { Iron }(\mathrm{III}) \text { oxide } & \text { Calcium oxide } & \text { Magnesium oxide } & \begin{array}{c}\text { Aluminium oxide } \\ \left(\mathrm{SiO}_{2}\right)\end{array} \\ \text { ignition } & \left(\mathrm{Fe}_{2} \mathrm{O}_{3}\right) & (\mathrm{CaO}) & (\mathrm{MgO}) & 1.50 & 23.67\end{array}$

provided by Hailuo Cement Company, China. The fly ash was classified as class II, the chemical composition and the gradation

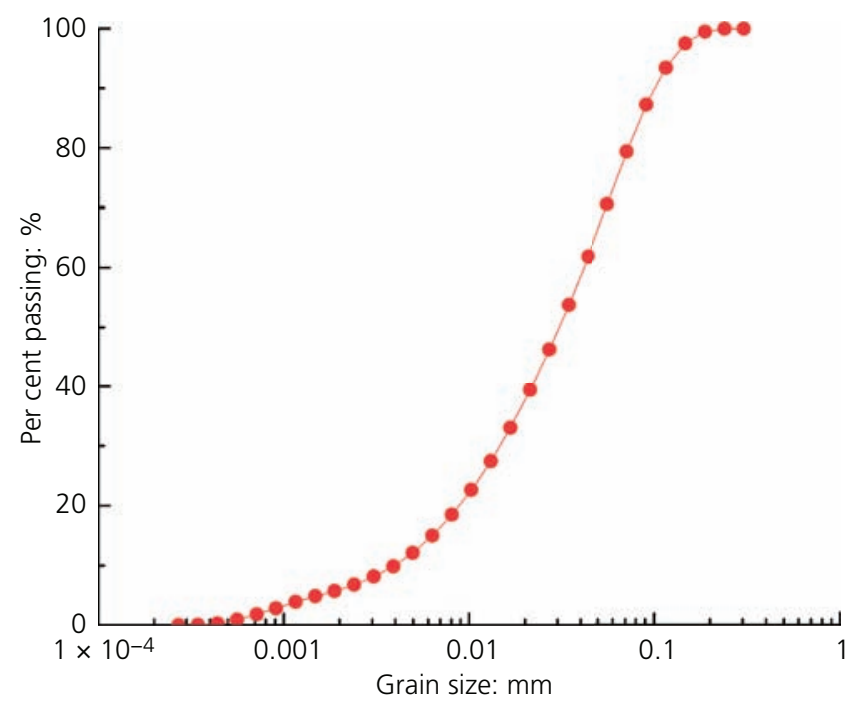

Figure 3. Fly ash gradation

Table 2. Test plan and UCSs

\section{Group name}

\section{CE: \%}

CA2-FA4

CA2-FA6

CA2-FA8

CA2-FA10

CA2-FA12

CA4-FA8

CA4-FA12

CA4-FA16

CA6-FA12

CA6-FA18

CA6-FA24

CA2-FA4-CE2

CA2-FA4-CE3

CA2-FA4-CE4

CA2-FA4-CE2-CASO.5

CA2-FA4-CE2-CAS1

CA2-FA4-CE2-CAS1.5

CA2-FA4-CE2-CAS2

CA2-FA4-CE2-CAS3

CA2-FA4-CE2-CAS4

CA2-FA4-CE2-CAS5

CA3-FA6-CE2-CAS1

CA3-FA6-CE3-CAS1

CA4-FA8-CE2-CAS1

CA4-FA8-CE4-CAS1

0

CA: $\%$

\section{FA: $\%$}

CAS: $\%$

UCS: MPa

Increase percentage after stabilisation: \%

\subsection{3}

0.248

0.320

0.194

0.209

0.256

0.255

0.274

0.306

0.327

0.308

0.326

0.451

0.600

0.367

0.378

0.431

0.464

0.442

0.469

0.444

0.522

0.542

0.582

0.927

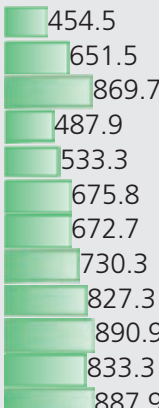

$\begin{array}{r}887.9 \\ \hline 1266.7 \\ \hline\end{array}$

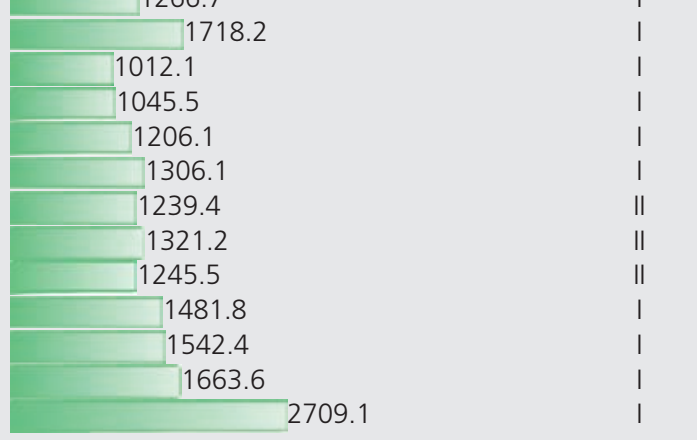

$C A$, lime; $C E$, cement; $F A$, fly ash; $C A S$, gypsum 
(c) The mixture was compacted into a steel mould layer by layer (three layers in total) within half an hour. Each layer interface surface was grooved.

(d) The soil sample was carefully removed from the mould by a hydraulic demolding instrument.

(e) Once finished, the specimens were sealed and cured under a constant temperature of $20^{\circ} \mathrm{C}$ and a humidity of $95 \%$ for 7 days.

The UCS tests were carried out by using a model E45 MTS universal tester (Figure 4) following BS 1377-7:1990 (BSI, 1990b). The specimens were $50 \mathrm{~mm}$ in diameter and $100 \mathrm{~mm}$ high. The loading rate of the UCS test carried out in this study was $1 \mathrm{~mm} / \mathrm{min}$ until the specimen failed. In each test group, the test was replicated at least three times to ensure that the standard deviation is no larger than 0.05 , and the averaged value was finally taken as the UCS of the test group.

\section{Results and discussion}

\section{Quantitative analysis}

The UCS test results are shown in Table 2. Figures 5-7 show the variation of UCS with different contents of the stabilisers. As can be seen in Figure 5(a), for given lime and fly ash contents, when the cement content was changed from 2 to $4 \%$, the UCS proportionally increased by a magnitude of $274 \mathrm{kPa}$. This linear

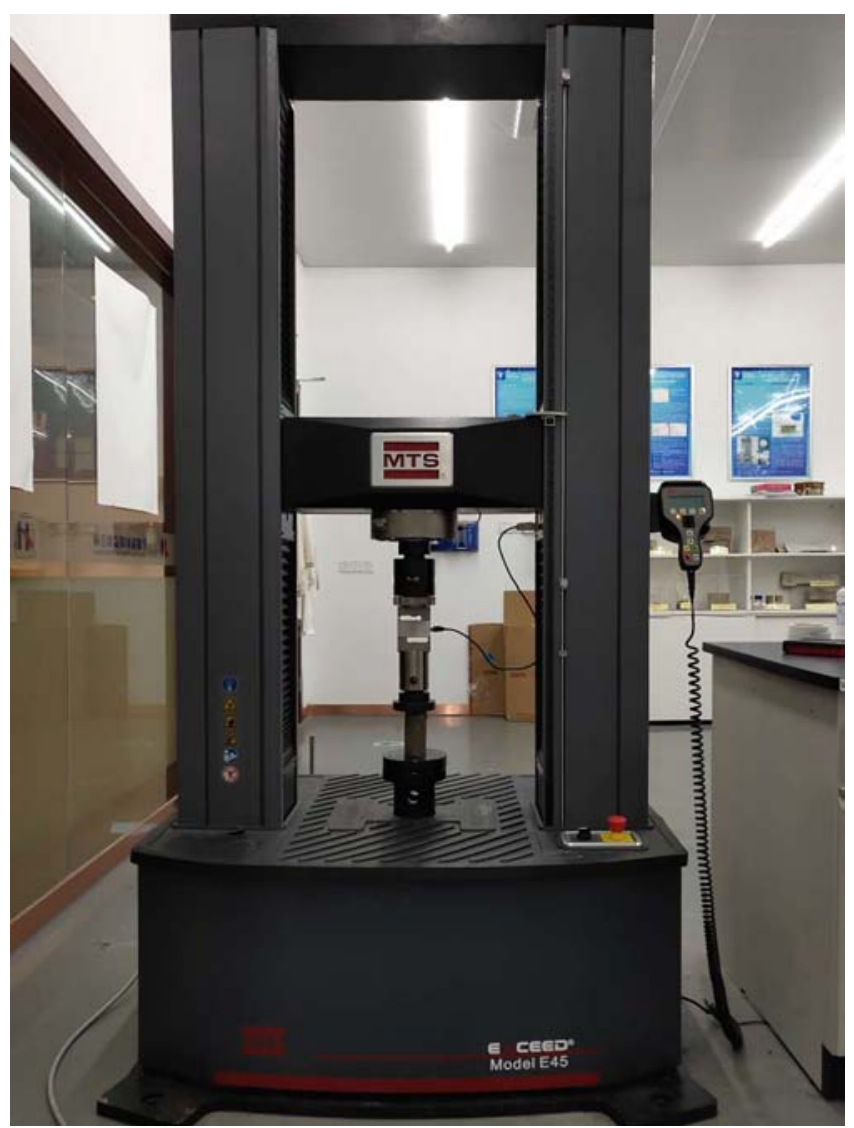

Figure 4. Photograph of the model E45 MTS universal tester relationship is consistent with previous findings (e.g. Pandey and Rabbani, 2017). When the cement content was increased from 0 to $2 \%$, the UCS was raised by $143 \mathrm{kPa}$.

Compared with cement, the influences of lime and fly ash contents are relatively small. For instance, when increasing the lime or fly ash content from 4 to $6 \%$, the UCS is raised by $51 \mathrm{kPa}$ (Figure 5(b)) and $65 \mathrm{kPa}$ (Figure 5(c)), respectively. Moreover, for a given lime content, there exists an optimum fly ash content that can maximise the UCS, which agrees with the finding of Kumar et al. (2007). It is further found that when the lime content is relatively high, the influence of the fly ash content becomes limited, as shown in Figure 6, and therefore, the increase of UCS in these cases is mainly attributed to the rise of the lime content. It can also be inferred from Figure 7 that the effect of cement is higher than the overall effect of lime and fly ash, since the growth trend of the UCS is changed from deceleration to acceleration due to some additional cement.

The influence of gypsum is demonstrated in Figure 5(d). It can be known that the strengths of the materials have been enhanced due to the addition of gypsum and an optimum content of gypsum is observed, above which the strength starts to decrease with increasing gypsum content. Huang and Hu (1998), Guo (2007), Huang et al. (2007) and Jin et al. (2014) had similar findings and explained that the excessive expansion of ettringites in gypsum may destroy the whole structure of the stabilised soil on the micro level, thereby resulting in a reduction in strength. Another possible reason is that the reaction process of gypsum is slow in the stabilised soil; if excess gypsum is added, the unreacted gypsum may weaken the bonds between soil particles and the cementitious compounds due to the platy shape of gypsum particles (Kolay and Pui, 2010; Kumar et al., 2007). When the gypsum content is increased from 0 to $2 \%$, the UCS is raised by $138 \mathrm{kPa}$, which is lower than that of cement but higher than those of lime and fly ash.

It can be concluded from the preceding quantitative analyses that cement has the most obvious effect on the UCS and the addition of gypsum can further increase its strength effectively. The effect of fly ash is limited, particularly when the lime content is high. Also, increasing the lime content alone could not affect the strength obviously. Moreover, it was found that a higher stabiliser content is normally in correspondence to a higher stiffness and a smaller deformation at failure, as shown in typical stress-strain curves in Figure 8. Also, note that the effects of fly ash and lime on the UCSs could become more obvious if a longer curing period is considered, as the hydration reaction rate for fly ash and pozzolanic reaction rate for lime are slow. Therefore, even though the effects of lime and gypsum are limited, their effectiveness on the long-term strength of stabilised soils needs further assessment in the future by considering longer curing periods.

\section{Grey relational analysis}

In the grey relational analysis system, the UCSs in Table 2 were used as the reference sequence $y_{0}(j)=y_{0}^{1}, y_{0}^{2}, \ldots, y_{0}^{m}$, where $m$ represents the number of the group tests. Meanwhile, the contents 


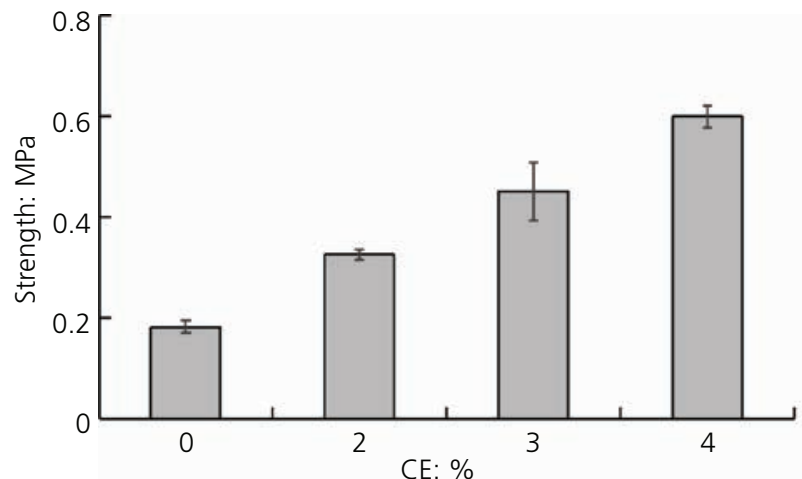

(a)

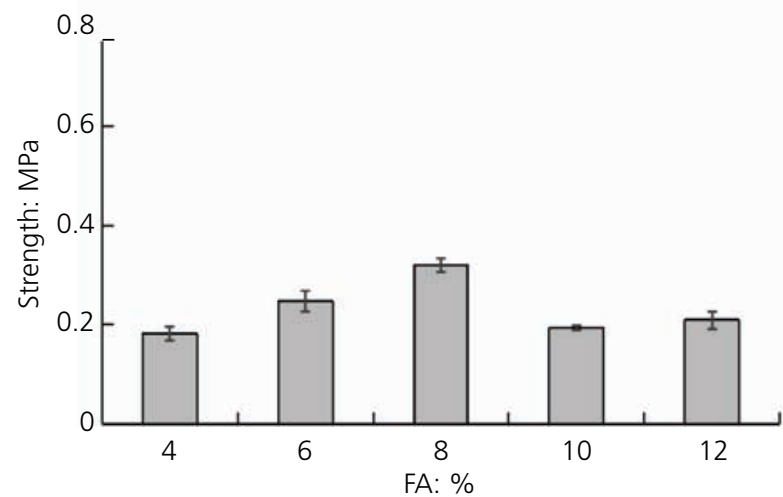

(c)

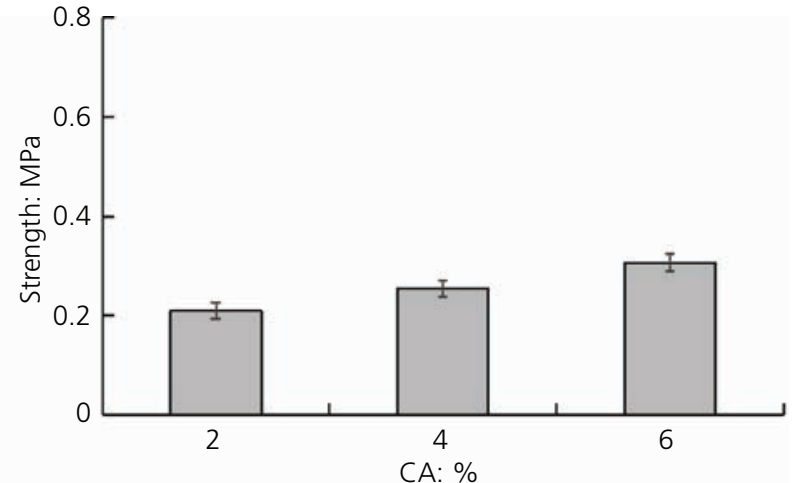

(b)

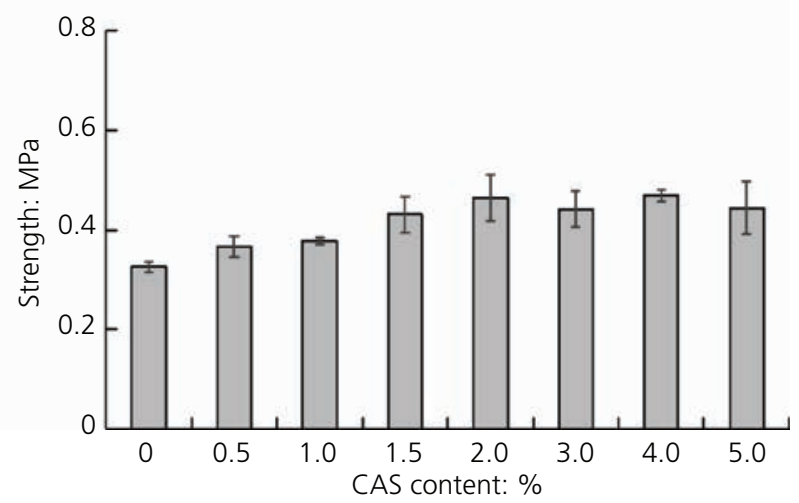

(d)

Figure 5. Influences of FA, CA and CE contents on UCS: (a) CA = 2\%, FA =4\%; (b) FA = 12\%; (c) CA = 2\%; (d) CA = 2\%, FA = 4\%, $\mathrm{CE}=2 \%$

of the four stabilisers were set as comparison sequences $y_{i}(j)=$ $y_{i}^{1}, y_{i}^{2}, \ldots, y_{i}^{m}$, where $i=1,2, \ldots, n$, representing the reference number of each stabiliser.

Following that, each sequence should be scaled using one normalisation method in order to eliminate the effect of various ranges of different sequences. In this study, five commonly used

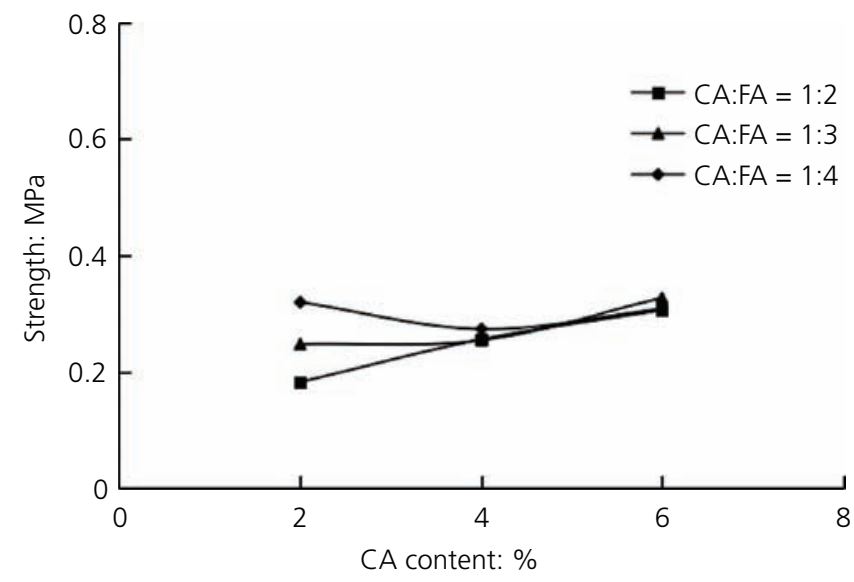

Figure 6. Influence of FA/CA ratio on UCS normalisation methods (Equations 1-5) were considered and the most effective one can be determined referring to the quantitative analyses. Note that among those methods, the maximisation method will lead to an infinite value of $x_{i}(j)$; thus, it will not be used in the following analysis. The data after each normalisation method are shown in Table 3.

(a) Initialisation

$$
\text { 1. } x_{i}(j)=\frac{y_{i}(j)}{y_{i}(1)} \quad y_{i}(1) \neq 0
$$

(b) Average

2. $x_{i}(j)=\frac{y_{i}(j)}{\bar{y}_{i}} \quad \bar{y}_{i}=\frac{1}{m} \sum_{j=1}^{m} y_{i}(j)$

(c) Range

3. $x_{i}(j)=\frac{y_{i}(j)-\min \left[y_{i}(j)\right]}{\max \left[y_{i}(j)\right]-\min \left[y_{i}(j)\right]}$ 


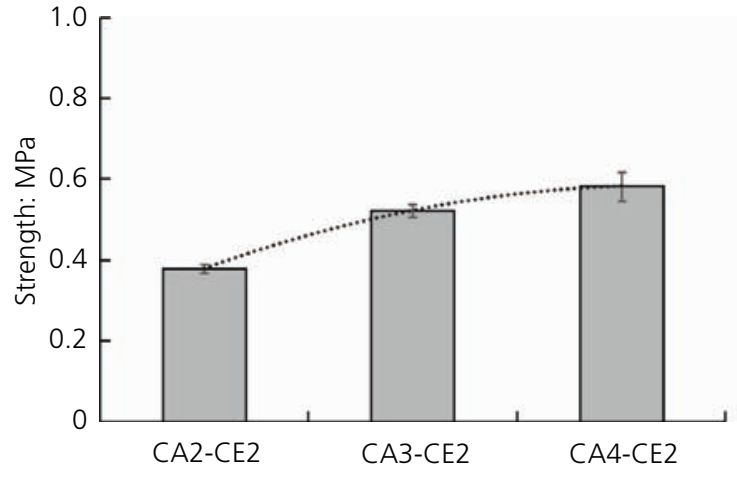

(a)

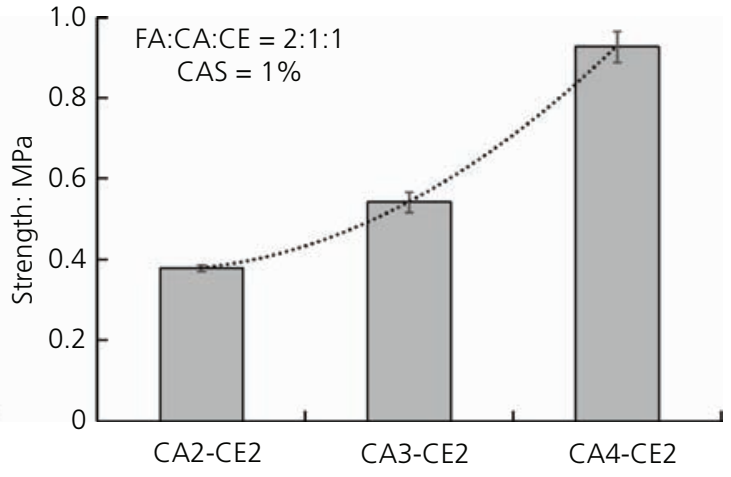

(b)

Figure 7. Influences of different proportions of stabilisers on UCS when (a) CA:FA $=1: 2$ and (b) CAS $=1 \%$

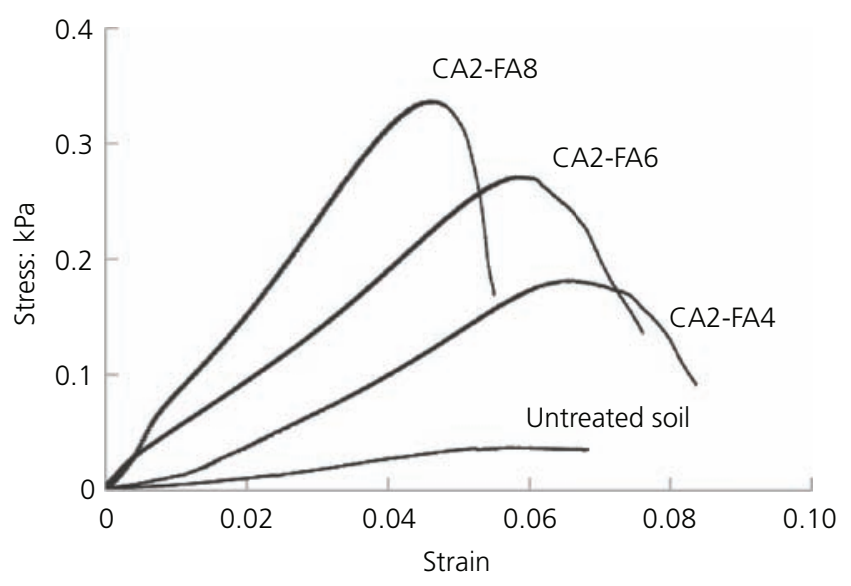

Figure 8. Stress-strain curves for raw and stabilised soils

(d) Maximisation

4. $x_{i}(j)=\frac{y_{i}(j)}{\min \left[y_{i}(j)\right]}$

(e) Minimisation

5. $x_{i}(j)=\frac{y_{i}(j)}{\max \left[y_{i}(j)\right]}$

Then, the absolute difference of sequences of $x_{0}$ and $x_{i}$ was calculated using Equation 6, in which the reference sequence $x_{0}(j)$ for each normalisation method is the corresponding UCS sequence in Table 3.

6. $\Delta_{i}(j)=\left|x_{0}(j)-x_{i}(j)\right|$
Based on those, the maximum and minimum values of $\Delta_{i}(j)$ were obtained:

7. $\Delta_{\max }=\max _{i} \max _{j}\left[\Delta_{i}(j)\right]$

8. $\Delta_{\min }=\min _{i} \min _{j}\left[\Delta_{i}(j)\right]$

Moreover, the relational coefficient of each test was calculated:

9. $\xi_{i}(k)=\frac{\Delta_{\min }+\rho \Delta_{\max }}{\Delta_{i}(j)+\Delta_{\max }}$

where $\rho$ is a resolution coefficient, between 0 and 1, normally taken as 0.5 .

Finally, the relevancy of each factor (stabiliser content) were obtained by calculating the relational coefficient:

10. $r_{i}=\frac{1}{n} \sum_{k=1}^{n} \xi_{i}(k)$

For the cases in this study, relational coefficients obtained using different normalisation methods are shown in Table 4 and compared in Figure 9. Normally, a factor is considered more influential on the reference value if its relational coefficient is relatively high (Subhash et al., 2020). Therefore, the order of the impact degree of various factors on the UCS can be obtained, as shown in Table 5. It can be seen that by using different normalisation methods, the orders are different. Using the average method, it appears that the effect of cement content is smaller than that of lime content, which is contradictory to the quantitative analysis. Table 4 also shows that either fly ash or gypsum has the lowest influence on the UCS. One possible reason is that the effects of fly ash and gypsum on the UCS are not 
Table 3. Normalised data (arbitrary units) by using four normalisation methods

\begin{tabular}{|c|c|c|c|c|c|c|c|c|c|c|c|c|c|c|c|c|c|c|c|c|}
\hline \multirow{2}{*}{ Group name } & \multicolumn{5}{|c|}{ Initialisation } & \multicolumn{5}{|c|}{ Average } & \multicolumn{5}{|c|}{ Range } & \multicolumn{5}{|c|}{ Minimisation } \\
\hline & CE & CA & FA & CAS & UCS & CE & CA & FA & CAS & UCS & CE & CA & FA & CAS & UCS & CE & CA & FA & CAS & UCS \\
\hline CA2-FA4-CE2-CAS0.5 & 1.0 & 1.0 & 1.0 & 1 & 1.00 & 1.47 & 0.68 & 0.51 & 0.60 & 0.93 & 1.47 & 0.68 & 0.51 & 0.60 & 0.93 & 0.5 & 0.33 & 0.17 & 0.1 & 0.40 \\
\hline CA2-FA4-CE2-CAS1 & 1.0 & 1.0 & 1.0 & 2 & 1.03 & 1.47 & 0.68 & 0.51 & 1.19 & 0.96 & 1.47 & 0.68 & 0.51 & 1.19 & 0.96 & 0.5 & 0.33 & 0.17 & 0.2 & 0.41 \\
\hline CA2-FA4-CE2-CAS1.5 & 1.0 & 1.0 & 1.0 & 3 & 1.18 & 1.47 & 0.68 & 0.51 & 1.79 & 1.10 & 1.47 & 0.68 & 0.51 & 1.79 & 1.10 & 0.5 & 0.33 & 0.17 & 0.3 & 0.46 \\
\hline CA2-FA4-CE2-CAS2 & 1.0 & 1.0 & 1.0 & 4 & 1.27 & 1.47 & 0.68 & 0.51 & 2.38 & 1.18 & 1.47 & 0.68 & 0.51 & 2.38 & 1.18 & 0.5 & 0.33 & 0.17 & 0.4 & 0.50 \\
\hline CA2-FA4-CE2-CAS3 & 1.0 & 1.0 & 1.0 & 6 & 1.21 & 1.47 & 0.68 & & 3.57 & 1.13 & 1.47 & 0.68 & 0.51 & 3.57 & 1.13 & 0.5 & 0.33 & 0.17 & 0.6 & 0.48 \\
\hline CA2-F & 1.0 & 1.0 & 1.0 & 8 & 1.28 & 1.47 & 0.68 & 0.51 & 4.76 & 1.19 & 1.47 & 0.68 & 0.51 & 4.76 & & 0.5 & 0.33 & 17 & 0.8 & 0.51 \\
\hline $\mathrm{CA} 2$ & 1.0 & 1.0 & 1.0 & 10 & 1.21 & 1.47 & 0.68 & 0.51 & 5.95 & 1.13 & 1.47 & 0.68 & 0.51 & 5.95 & 1.13 & 0.5 & 0.33 & .17 & 1.0 & 0.48 \\
\hline & 1.0 & 1.5 & 1.5 & 2 & 1.42 & 1.47 & 1.01 & 0.76 & 1.19 & 1.33 & 1.47 & 1.01 & 0.76 & 1.19 & 1.33 & 0.5 & 0.50 & .25 & 0.2 & 0.56 \\
\hline AS1 & 1.5 & 1.5 & 1.5 & 2 & 1.48 & 2.21 & 1.01 & 0.76 & 1.19 & 1.38 & 2.21 & 1.01 & 0.76 & 1.19 & 1.38 & 0.8 & 0.50 & 0.25 & 0.2 & 0.58 \\
\hline CA4-FA8-CE2-C & 1.0 & 2.0 & 2.0 & 2 & 1.59 & 1.47 & 1.35 & 1.01 & 1.19 & 1.48 & 1.47 & 1.35 & 1.01 & 1.19 & 1.48 & 0.5 & 0.67 & 0.33 & 0.2 & 0.63 \\
\hline CA4-FA8-CE4-CAS1 & 2.0 & 2.0 & 2.0 & 2 & 2.53 & 2.94 & 1.35 & 1.01 & 1.19 & 2.36 & 2.94 & 1.35 & 1.01 & 1.19 & 2.36 & 1.0 & 0.67 & 0.33 & 0.2 & 1.00 \\
\hline $\mathrm{CA} 2$ & 0 & 1.0 & 1.0 & 0 & 0.50 & 0 & 0.68 & 0.51 & 0 & 0.46 & 0 & 0.68 & 0.51 & 0 & 0.46 & 0 & 0.33 & 0.17 & 0 & 0.20 \\
\hline CA2-FA6 & 0 & 1.0 & 1.5 & 0 & 0.68 & 0 & 0.68 & 0.76 & 0 & 0.63 & 0 & 0.68 & 0.76 & 0 & 0.63 & 0 & 0.33 & 0.25 & 0 & 0.27 \\
\hline CA2 & 0 & 1.0 & 2.0 & 0 & 0.87 & 0 & 0.68 & 1.01 & 0 & 0.81 & 0 & 0.68 & 1.01 & 0 & 0.81 & 0 & 0.33 & 0.33 & 0 & 0.34 \\
\hline CA2-FA & 0 & 1.0 & 2.5 & 0 & 0.53 & 0 & 0.68 & 1.26 & 0 & 0.49 & 0 & 0.68 & 1.26 & 0 & 0.49 & 0 & 0.33 & 0.42 & 0 & 0.21 \\
\hline CA2-F/ & 0 & 1.0 & 3.0 & 0 & 0.57 & 0 & 0.68 & 1.52 & 0 & 0.53 & 0 & 0.68 & 1.52 & 0 & 0.53 & 0 & 0.33 & 0.50 & 0 & 0.23 \\
\hline CA4 & 0 & 2.0 & 2.0 & 0 & 0.70 & 0 & 1.35 & 1.01 & 0 & 0.65 & 0 & 1.35 & 1.01 & 0 & 0.65 & 0 & 0.67 & 0.33 & 0 & 0.28 \\
\hline CA4-FA12 & 0 & 2.0 & 3.0 & 0 & 0.69 & 0 & 1.35 & 1.52 & 0 & 0.65 & 0 & 1.35 & 1.52 & 0 & 0.65 & 0 & 0.67 & 0.50 & 0 & 0.27 \\
\hline CA4-FA16 & 0 & 2.0 & 4.0 & 0 & 0.75 & 0 & 1.35 & 2.02 & 0 & 0.70 & 0 & 1.35 & 2.02 & 0 & 0.70 & 0 & 0.67 & 0.67 & 0 & 0.30 \\
\hline CA6-FA12 & 0 & 3.0 & 3.0 & 0 & 0.83 & 0 & 2.03 & 1.52 & 0 & 0.78 & 0 & 2.03 & 1.52 & 0 & 0.78 & 0 & 1.00 & 0.50 & 0 & 0.33 \\
\hline CA6-FA18 & 0 & 3.0 & 4.5 & 0 & 0.89 & 0 & 2.03 & 2.27 & 0 & 0.83 & 0 & 2.03 & 2.27 & 0 & 0.83 & 0 & 1.00 & 0.75 & 0 & 0.35 \\
\hline CA6-FA24 & 0 & 3.0 & 6.0 & 0 & 0.84 & 0 & 2.03 & 3.03 & 0 & 0.78 & 0 & 2.03 & 3.03 & 0 & 0.78 & 0 & 1.00 & 1.00 & 0 & 0.33 \\
\hline CA2-FA4-CE2 & 1.0 & 1.0 & 1.0 & 0 & 0.89 & 1.47 & 0.68 & 0.51 & 0 & 0.83 & 1.47 & 0.68 & 0.51 & 0 & 0.83 & 0.5 & 0.33 & 0.17 & 0 & 0.35 \\
\hline CA2-FA4-CE3 & 1.5 & 1.0 & 1.0 & 0 & 1.23 & 2.21 & 0.68 & 0.51 & 0 & 1.15 & 2.21 & 0.68 & 0.51 & 0 & 1.15 & 0.8 & 0.33 & 0.17 & 0 & 0.49 \\
\hline CA2-FA4-CE4 & 2.0 & 1.0 & 1.0 & 0 & 1.64 & 2.94 & 0.68 & 0.51 & 0 & 1.53 & 2.94 & 0.68 & 0.51 & 0 & 1.53 & 1.0 & 0.33 & 0.17 & 0 & 0.65 \\
\hline
\end{tabular}

Table 4. Correlation coefficients

\begin{tabular}{|c|c|c|c|c|c|}
\hline Normalisation method & Lime & Fly ash & Cement & Gypsum & Order of impact on UCS \\
\hline Initialisation & 0.891 & 0.835 & 0.910 & 0.790 & Cement $>$ lime $>$ fly ash $>$ gypsum \\
\hline Average & 0.842 & 0.787 & 0.815 & 0.746 & Lime $>$ cement $>$ fly ash $>$ gypsum \\
\hline Range & 0.609 & 0.595 & 0.757 & 0.707 & Cement $>$ gypsum $>$ lime $>$ fly ash \\
\hline Minimisation & 0.700 & 0.621 & 0.723 & 0.569 & Cement $>$ lime $>$ fly ash $>$ gypsum \\
\hline
\end{tabular}

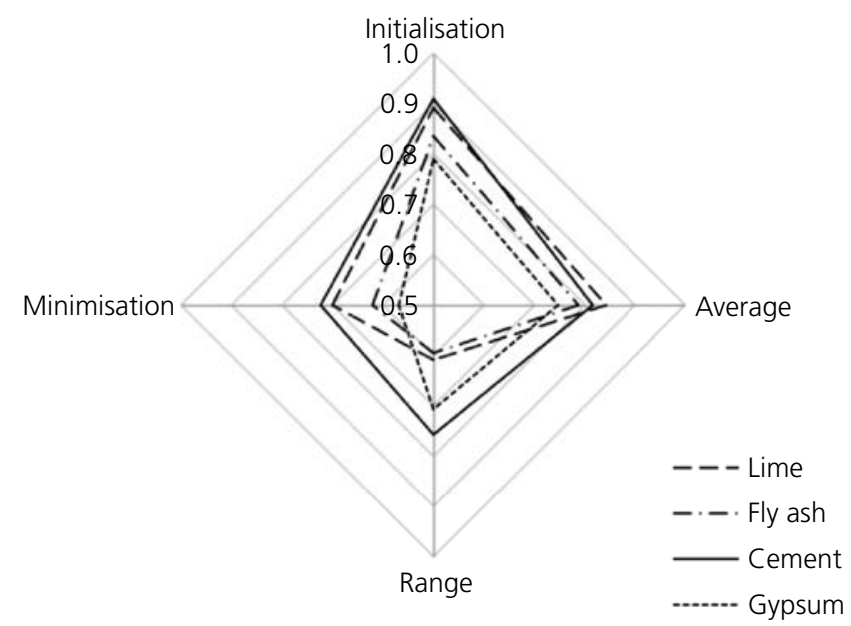

Figure 9. Comparison of correlation coefficients for different normalisation methods and stabilisers always positive. Optimum contents can be observed in Figures 5(c) and 5(d). Therefore, grey relational analyses were further carried out by only using the data within the increase stage. All test results in Table 2 were divided into two groups. Group I refers to the cases where the rise of the stabiliser content has a clear positive impact, while group II represents the rest. Accordingly, the relational coefficients and the orders of impact were obtained and are shown in Table 5. According to the results obtained through the quantitative analysis, it is clear that the order obtained by the range method is more reasonable when compared with those of the other three methods.

\section{Conclusion}

This study investigated the effects of four stabilisers on the UCS of a stabilised fine soil using quantitative analysis and grey relational analysis. In the quantitative analysis, it was found that there exists a positive linear relationship between the cement content and UCS. The effect of the cement content on the UCS is higher than that of gypsum, followed by those of lime and fly ash. For both fly ash and gypsum, there exist optimum contents that can maximise the UCS. 
Table 5. Correlation coefficients for the increase stage

\begin{tabular}{|c|c|c|c|c|c|}
\hline Normalisation method & Lime & Fly ash & Cement & Gypsum & Order of impact on UCS \\
\hline Initialisation & 0.949 & 0.930 & 0.930 & 0.833 & Lime $>$ cement $\approx$ fly ash $>$ gypsum \\
\hline Average & 0.946 & 0.920 & 0.911 & 0.799 & Lime $>$ fly ash $>$ cement $>$ gypsum \\
\hline Range & 0.655 & 0.653 & 0.734 & 0.710 & Cement $>$ gypsum $>$ lime $\approx$ fly ash \\
\hline Minimisation & 0.770 & 0.733 & 0.752 & 0.617 & Lime $>$ cement $>$ fly ash $>$ gypsum \\
\hline
\end{tabular}

In grey relational analysis, the selection of the normalisation method can change the correlation ranking of the stabilisers with respect to UCS. In this study, the analysis using the rangenormalisation method gives a reasonable ranking of the stabilisers, whereas the average method is not applicable. The order of impact is also affected by the changing trend of the UCS, which is not explicitly shown in the calculated relational coefficients; therefore, grey relational analysis should be conducted with care when a change of trend is possible.

It can be further concluded that cement is the most effective stabiliser for fine soil. The addition of a proper content of gypsum can further increase its strength. The effects of quick lime and fly ash are limited on the early-stage (7-day) strength, but their influences on the long-term strength need further assessments.

\section{Acknowledgements}

Financial support from the Ningbo S\&T Innovation 2025 Major Special Programme (grant 2019B10048), the Ningbo Natural Science Foundation (grant 2018A610350) and the Ningbo Haishu Science and Technology Bureau is gratefully acknowledged. The Zhejiang Provincial Department of Science and Technology is acknowledged for this research under its provincial Key Laboratory Programme (2020E10018). The first and second authors contributed equally to this work.

\section{REFERENCES}

Åhnberg H and Holm G (2009) Influence of laboratory procedures on properties of stabilized soil specimens. Proceedings of the 2009 International Symposium on Deep Mixing and Admixture Stabilization, Okinawa, Japan.

Bell F (1995) Cement stabilization and clay soils, with examples. Environmental and Engineering Geoscience 1(2): 139-151, https://doi. org/10.2113/gseegeosci.I.2.139.

Bell F (1996) Lime stabilization of clay minerals and soils. Engineering Geology 42(4): 223-237, https://doi.org/10.1016/0013-7952(96)00028-2.

BSI (1990a) BS 1377-2:1990: Methods of test for soils for civil engineering purposes. Classification tests. BSI, London, UK.

BSI (1990b) BS 1377-7: Methods of test for soils for civil engineering purposes. Shear strength tests (total stress). BSI, London, UK.

BSI (2015) BS 5930:2015: Code of practice for ground investigations. BSI, London, UK.

Chen M, Yang G and Yu L (2013) Experimental study on solidification and stabilization of polluted silt using fly ash and sodium hydroxide. Journal of Huazhong University of Science and Technology (Natural Science Edition) 41(10): 123-127, https://doi.org/10.13245/j.hust.2013.10.013.

Deng J (1989) Introduction to grey system theory. Journal of Grey System 1: $1-24$.

Feng P, Hao L, Huo C et al. (2014) Rheological behavior of coal bio-oil slurries. Energy 66: 744-749, https://doi.org/10.1016/j.energy.2014.01. 097.
Gau H, Hsieh C and Liu C (2006) Application of grey correlation method to evaluate potential groundwater recharge sites. Stochastic Environmental Research and Risk Assessment 20(6): 407-421https:// doi.org/10.1007/s00477-006-0034-9.

Guo Y (2007) Study on Stabilization of Muddy Soil and Mechanical Properties of Stabilized Soil. PhD thesis, Zhejiang University, Hangzhou, China.

He Y, Zhang X, Zhang Y and Zhou Y (2014) Effects of particle characteristics of lightweight aggregate on mechanical properties of lightweight aggregate concrete. Construction and Building Materials 72: 270-282, https://doi.org/10.1016/j.conbuildmat.2014.07.043.

Huang $X$ and Hu T (1998) Experimental study on stabilization of soft soil with waste gypsum and cement. Chinese Journal of Geotechnical Engineering 20(5): 72-76.

Huang X, Xu S and Ning J (2007) Experimental research on stabilized soft soils by alumina bearing modifier. Chinese Journal of Rock Mechanics and Engineering 26(1): 156-161, https://doi.org/10.3321/j.issn:10006915.2007.01.022.

Indraratna A, Balasubramanian A and Khan M (1995) Effect of fly ash with lime and cement on the behavior of a soft clay. Quarterly Journal of Engineering Geology and Hydrogeology 28: 131-142, https://doi.org/10.1144/GSL.QJEGH.1995.028.P2.04.

Jauberthie R, Rendell F, Rangeard D and Molez L (2010) Stabilization of estuarine silt with lime and/or cement. Applied Clay Science 50(3): 395-400, https://doi.org/10.1016/j.clay.2010.09.004.

Jin J, Li J and Li X (2014) Test research on gypsum reinforced soft soil. Architecture Technology 45(4): 349-352, https://doi.org/10.13731/j. issn.1000-4726.2014.04.016.

Kogbara R, Al-Tabbaa A, Yi Y and Stegemann JA (2013) Cement-fly ash stabilization/solidification of contaminated soil: performance properties and initiation of operating envelopes. Applied Geochemistry 33: 64-75, https://doi.org/10.1016/j.apgeochem.2013.02.001.

Kolay P and Pui M (2010) Peat stabilization using gypsum and fly ash. Journal of Civil Engineering, Science and Technology 1(2): article 75, https://doi.org/10.33736/jcest.75.2010.

Kumar A, Walia B and Bajaj A (2007) Influence of fly ash, lime, and polyester fibers on compaction and strength properties of expansive soil. Journal of Materials in Civil Engineering 19(3): 242-248, https:// doi.org/10.1061/(ASCE)0899-1561(2007)19:3(242).

Lin D, Lin K, Hung M and Lou H (2007) Sludge ash/hydrated lime on the geotechnical properties of soft soil. Journal of Hazardous Materials 145(1-2): 58-64, https://doi.org/10.1016/j.jhazmat.2006.10.087.

Mishra P, Das D, Ukamanal M, Routara B and Sahoo A (2015) Multiresponse optimization of process parameters using Taguchi method and grey relational analysis during turning AA 7075/SiC composite in dry and spray cooling environments. International Journal of Industrial Engineering Computations 6(4): 445-456, https://doi.org/ 10.5267/j.ijiec.2015.6.002.

Mousavi S and Wong L (2015) Performance of compacted and stabilized clay with cement, peat ash and silica sand. Jordan Journal of Civil Engineering 9(1): 20-32.

Ouhadi V, Yong R, Amiri M and Ouhadi M (2014) Pozzolanic consolidation of stabilized soft clays. Applied Clay Science $\mathbf{9 5}$ : 111-118, https://doi.org/10.1016/j.clay.2014.03.020.

Pandey A and Rabbani A (2017) Soil stabilisation using cement. International Journal of Civil Engineering and Technology 8(6): 316-322. 
Geotechnical Research

Volume 7 Issue 4
Influence of stabilisers on the unconfined

compressive strength of a fine soil

Feng, Liu, Wang and $\mathrm{Hu}$
Petry TM and Little DN (2002) Review of stabilization of clays and expansive soils in pavements and lightly loaded structures - history, practice, and future. Journal of Materials in Civil Engineering 14(6): 447-460, https://doi.org/10.1061/(ASCE)0899-1561(2002)14:6(447).

Prusiski J and Bhattacharja S (1999) Effectiveness of Portland cement and lime in stabilizing clay soils. Transportation Research Record 1652(1): 215-227, https://doi.org/10.3141/1652-28.

Purwanto H, Setiobudi A and Rustam R (2020) Stabilization of soft clay using a gypsum plafond waste based on CBR testing. International Journal of Scientific \& Technology Research 9(2): 963-968, https:// doi.org/10.1088/1757-899X/620/1/012039.

Sherwood P (1993) Soil Stabilization with Cement and Lime. Her Majesty's Stationery Office, London, UK.

Sivapullaiah PV and Jha AK (2014) Gypsum induced strength behaviour of fly ash-lime stabilized expansive soil. Geotechnical and Geological Engineering 32(5): 1261-1273, https://doi.org/10.1007/s10706-0149799-7.

Su Y, Luo Z and Li X (2012) Grey correlation analysis method for cut-andfill roadbed slope stability based on uniform experiment. Rock and Soil Mechanics 33(8): 2259-2264.
Subhash C, Yaragal B, Chethan K and Jitin C (2020) Durability studies on ferrochrome slag as coarse aggregate in sustainable alkali activated slag/fly ash based concretes. Sustainable Materials and Technologies 23: article e00137, https://doi.org/10.1016/j.susmat.2019.e00137.

Taştan EO (2005) Stabilization of Organic Soils Using Fly Ash. MSc thesis, University of Wisconsin-Madison, Madison, WI, USA.

Tsuchida T and Tang Y (2015) Estimation of compressive strength of cement-treated marine clays with different initial water contents. Soils and Foundations 55(2): 359-374, https://doi.org/10.1016/j.sandf.2015. 02.011 .

Wang D and Xu W (2013) Experimental study on long-term strength and deformation properties of solidified sediments. Journal of Central South University (Science and Technology) 44(1): 332-339.

Wang Y, Yin K and An G (2004) Grey correlation analysis of sensitive factors of landslide. Rock and Soil Mechanics 25(1): 91-93.

Zhang $Y$ and Zhang X (2007) Grey correlation analysis between strength of slag cement and particle fractions of slag powder. Cement \& Concrete Composites 29(6): 498-504, https://doi.org/10.1016/j. cemconcomp.2007.02.004.

\section{How can you contribute?}

To discuss this paper, please submit up to 500 words to the editor at journals@ice.org.uk. Your contribution will be forwarded to the author(s) for a reply and, if considered appropriate by the editorial board, it will be published as a discussion in a future issue of the journal. 